\title{
Cultivating Humanizing Change Imagination, Creativity and Collaboration
}

\author{
Anne Riggs \\ Artists in Community International, Melbourne, Australia
}

\begin{abstract}
Imagination, creativity, and collaboration are essential in cultivating humane and positive change in the lives of people who exist, largely un-noticed and uncared for, at the fringes of society. Without them, it is impossible to effect meaningful and beneficial change. In 2015 and 2016, Artists in Community International was invited to collaborate with social, child protection and health workers trying to provide services in the brick kilns and surrounding communities in rural Nepal. A culture of mistrust between the brick kiln workers and service providers had prevented the delivery of much needed services into these harsh working environments. We were invited to help build trust, develop community relationships, and contribute to raising community awareness around education and social, health and hygiene issues. It was an invitation to help improve the lives of people living and working in and around the brick kilns - extremely bleak environments that generate a myriad of health and social problems. This paper uses those recent projects to discuss how igniting the imagination through arts practice and interactions with artists can transform despair into possibility, then humane and positive change, particularly for those who believe none is available to them. We are offering this as a model for developing more collaboration between social and community workers with artists to cultivate humanizing change wherever it is needed.
\end{abstract}

Keywords Art, Community, Nepal, Brick Kilns

The development of a creative individual, one who strives for the future, is enabled by creative imagination that is embodied in the present. Lev Vytogsky [1]

\section{Introduction}

As an artist talking to a room full of social workers I sometimes see myself as the cuckoo in the swallow's nest - a welcome one, of course, and today is no exception. I am so glad that our professions can meet and share in conversations about issues that mean so much to all of us.

Like many artists working in the community, I tend to sit outside the main practices of an organisation yet work deeply within it. My work in a cancer hospital, sexual assault organisation, and the brick kilns are some examples of this. Artists can slip under the radar; and work in between ... in between the person and a label, in between desire and fear, between the past and the future, trauma and hope, revolution and stagnation. We rattle the cage too. And we can get under the skin. We get in between those who want change and have no idea of how to achieve it, and between people who are vulnerable and those who wish to trample on that vulnerability. Working under the radar, we are able to initiate valuable and much-needed change and remarkably, sometimes, without being caught up in all that stifles so much possibility.

My arts practice has taken me into the most extraordinary places and situations, and amongst the people who inhabit these places. Like many social workers, artists are invited into help soothe a weeping wound, encourage a viable life, put sorrow to rest. I often pause to reflect, "How did I get here?" The answer is, that it is because of the same reasons that you are all here, and doing the work you do - a deep interest in humanity and equity, and a desire to contribute to others living the lives they would like to lead, to live the lives that don't even yet know they want to lead, to contribute to their family and community, to be safe, and feeling the sense of wellbeing. 


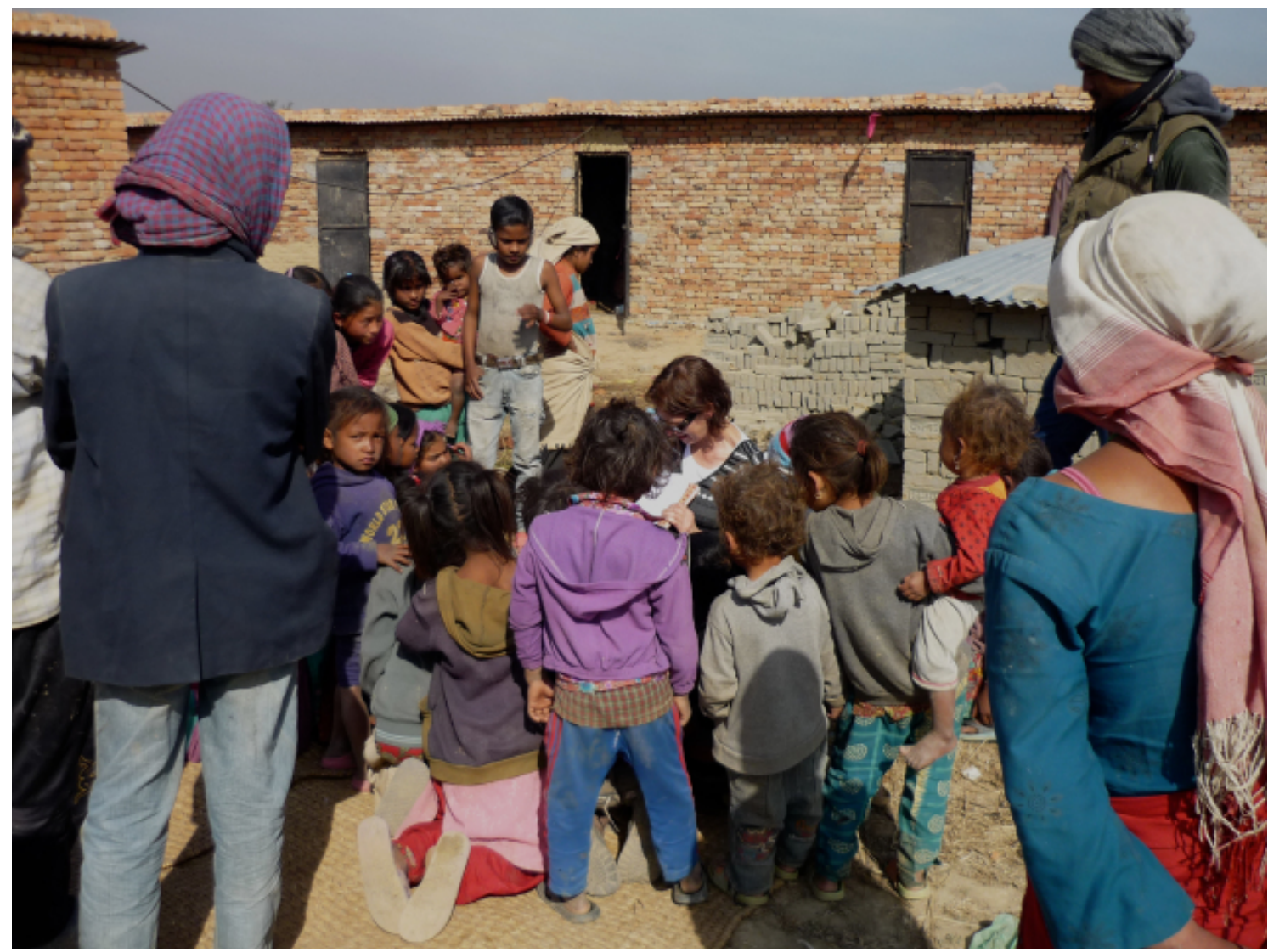

Figure 1. The author demonstrating drawing techniques to a brick kiln community, Nepal

\section{Imagination, Creativity and Collaboration}

This conference is about fostering conversations. I am here to insert the artist's voice and practice in community development into that conversation. By focusing on three themes, imagination, creativity and collaboration, things that are crucial to affecting the change that people desire, and need, I want to evoke some curiosity in you. I want to awaken the imagination in ourselves as workers and in the people with whom we work ... to inspire some thinking, and action, about our practices and the services we offer... to transform that imagination into possibility, then humane and positive change, especially for those who believe none is available to them, such as the uneducated, those born into low-castes and indentured labourers.

I am a co-founder, with performing artist Alex Pinder, of Artists in Community International, a tiny organisation. Alex and I work together, and separately, to inspire and engage communities, individuals, and leaders to be imaginative and creative. We do this through art-making and by providing inclusive, challenging, dynamic and joyous programs that also encourage better education and health practices. Whilst much of our work occurs in vulnerable communities in Nepal and India and in collaboration with community leaders in those places, we also work in Australia and beyond.

The name Artists in Community speaks to the creative part in all of us. "This hard-wired creativity, the inheritance of every child ever born across space and time", as writer Jeanette Winterson describes it [2]. “... The desire to play, to imagine, to tell and hear stories, to be taken on wild imaginative journeys and to see ourselves reflected back at us." It reflects a view that the arts and community are relevant, are worthwhile, are the things that sustain us, especially in times of uncertainty, when other things fall away or have yet to be built. We are compelled to consider creativity as the rule rather than the exception, and that professional artists and arts organisations are essential contributors to assisting people and communities gain insights, reach their potential and find meaning.

What place does imagination have in community development? What does a society look like when individuals and communities are able to breathe imagination into our lives?

\section{Nepal}

We began our work in Nepal because of this family of conferences, and the relationships and friendships that have formed over the years because of them. It was in Nepal that we first met people from the Nepal School of Social Work and went on, that year and each year since, to run a community arts and training programs with their staff, 
students, and people with whom the school works. And through NSSW, an organisation called UEMS: The Urban Environment Management Society, and READ who run community library and resource centres throughout rural Nepal.

We work with many communities in Nepal, but in this paper I want to tell you about collaborations that emerged from our relationship with the School of Social Work: with UEMS, in the brick kilns, and with READ, a community library. These two organisations invited us to help them address some pressing social issues.

Nepal is a poor country. It's trying to establish itself after years of civil war and with a government that is not yet capable of governing well for all its citizens. Its capital city, Kathmandu, is without the necessary infrastructure to cope with its fast-growing population. Displacement, inadequate health, and education services, severe pollution, people struggling to make a living in this country where there is high unemployment are some areas that require urgent attention.

Added to that are two recent major natural disasters - the avalanche in 2013 and the earthquake in April 2015 - events that hugely impacted the country's limited resources, and have taken a tremendous emotional toll on its citizens. The loss of much-needed tourist dollars as a consequence and the 15 hours a day of load shedding doesn't help. Nor did the blockade imposed by India just four months after the earthquake which prevented fuel for the buses, cooking, or heating the country and other much-needed materials and resources from coming into Nepal. The blockade lasted for six months.

The combination of all these imposes a miserable existence on the Nepali people. The problems are deep and widespread; and even the very considerable strengths and resilience of the Nepali people does not seem to be enough to overcome them. Our colleagues - teachers, social workers, and health and child protection workers - felt overworked before the earthquake, and overwhelmed after it.

\section{Observing Impediments to Change}

In his talk to graduating School for Education students Harvard Dean, James Ryan, asked them to remember a few questions that would be useful guides to them in their futures [3]. One is: I Wonder ... I wonder why followed by I wonder if.

Artists have a well-developed 'imagination muscle' as Patrick Lawrence, a Director at the Asylum Seeker Resource Centre, calls it [4]. This is what we do. We imagine, create, imagine, and create. He asks why is it that so many people involved in the centre are creatives? And goes on to suggest that the highly developed imagination of the artist naturally leans towards being able to imagine - in this case empathize with - the plight of others, particularly those who are suffering. I wonder why there is so much suffering?

Being able to empathize is one thing, a start; but it is not enough for effective change. However, it is that the other aspect of the artist character, creativity, that enables us to ask the second part of James Ryan's question, I wonder if ... I wonder if we do this, whether we can be alleviate some of this suffering. I wonder if we developed the imagination, utilised creativity and collaborated more openly with others whether we can really make a difference to how we work and the effects that work can have?

Professor Craig Calhoun, a former Director and President of the London School of Economics, in his talk, Can imagination change the world? Spoke of the theory of TINA (There Is No Alternative [5]. Former UK Prime Minister Margaret Thatcher coined this term, TINA, to defend the sweeping changes the government was making to economic policy [6]. Calhoun calls this theory, most often applied by government and business to justify, to shut down, to insist, "the tyranny of TINA". Lines like: We have to cut services there is no alternative - if we are to keep/get the budget into surplus are commonplace across all forms of government.

We have all heard similar examples of TINA in action.

The writer, Jeanette Winterson, talks about "false binaries", which is a slightly different take on the same thing. False binaries are the false questions and false choices which aren't necessary and don't make sense yet we are forced to make them. An example is a choice between the arts and health funding, or education or giving aid to developing countries or tax cuts, that we in Australia are too often expected to make.

Neither TINA nor false binaries are for artists or community/social workers. They totally shut down the curious questions, the $I$ wonder why? as well as shut down the imaginative and creative thoughts that come with the next question: I wonder if. They not do attempt to find ways to cultivate humanizing change. Those who work in the glare of TINA aim to impose, rather than collaborate; to be self-serving rather than community or society-focused; to be dominating rather than consultative. There is always something to be gained when curiosity and imagination are aroused.

What might Nepal, or any developing country look like if questions that started with: I wonder why, then I wonder if...started a process of imagining, then implementing an alternative to ... its caste system and to outdated roles of women and girls? And what might Australia look like if we chose not to pitch ourselves headlong into false binaries like: detention centres or terrorists? If we asked these questions to unbind ourselves from this sort of thinking, we would find that our countries, our cultures, could be humanely changed and changed to be humane. 


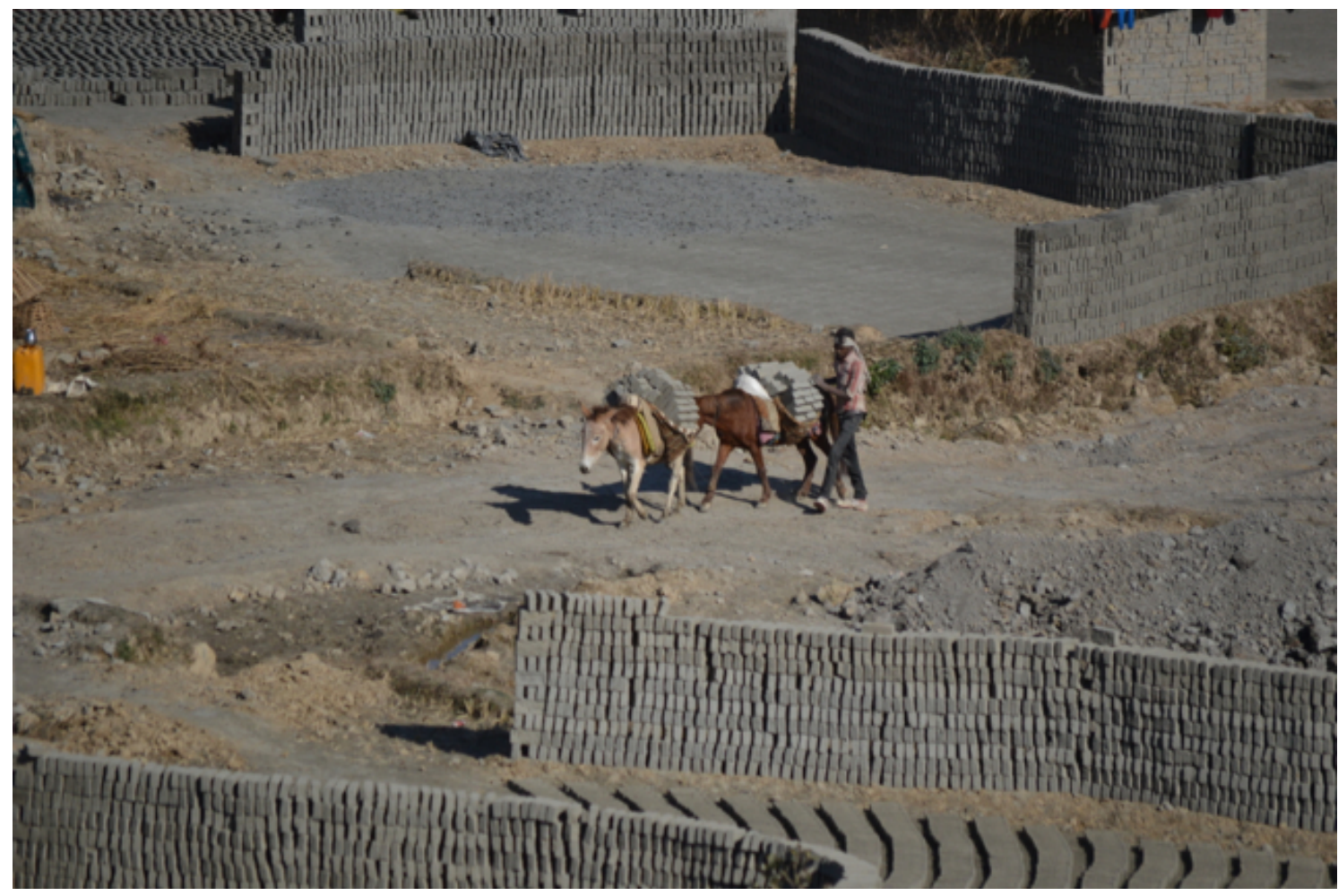

Figure 2. Inside a brick kiln, Nepal

\section{Inside the Brick Kilns}

The bricks kilns in Nepal are an archaic industry and in their current form have no place in the modern world. Alex and I were at first incredulous to witness people carrying up to 37 raw bricks on their back into the kilns and others emptying the kiln in a same way; and young boys driving hapless donkeys laden with bricks to and from the kilns. Workers feed coal into the huge and voracious kiln, and its vile smoke belches out across the valley, blurring mountain views and choking the air. We witnessed the workers' pitiful living conditions, and learnt of their piecework wages. We also learnt about debt, indentured labour, child labour and young children being 'leased' from their parents for the brick season that lasts for six months of the year. We heard about poor maternal health, disease, child deaths, and more.

Childhood, sexual and family abuse is known to be widespread in the kilns but it has been difficult for our colleagues at UEMS, particularly the child protection workers, to build trust enough with the brick workers to effectively tackle it. Those workers have lots of imagination, and asked the question I wonder if ... working with these artists might help us address these sensitive and silent issues more successfully? In an example of artists working in between: in between the fear and suspicion for the child protection / social workers and the work that needed to be done to make people safe, a collaboration between the social workers and us was forged, and a direction was found that became part of the much-needed solution to overcome this vexing problem.
The projects that have run over two years, and grew substantially in the second year, began with fun, so lacking in this environment yet so great in bringing people together. Alex is a performing artist with a specialty in mime and clowning, a largely unknown art form amongst the brick workers. It is not long before the whole community is involved and laughing.

As UEMS were also trying to encourage child enrolment into the school, and women to engage with the maternal health centre, we set out to run a program that taught skills and concepts to broaden the brick workers' outlook to the their own wellbeing and future. An example of using the arts to help children into education was teaching them colours and shapes, in Nepali and English, then showing artworks that incorporate these ideas, such as work by German Artist, Paul Klee. We go over these concepts each day to ensure knowledge is embedded.

At the same time, our colleagues from UEMS participate fully in the project; they are getting to know people, supporting their efforts, drawing, chatting, and helping. They are also our translators. Gradually barriers are broken down. As relationships grew, UEMS workers could identify and address health issues, as well as bring relevant topics gently into the conversation.

\section{Cultivating the Imagination}

Imagination is often portrayed as an internal activity, the free flight of the thoughts [7]. Its direction, at first glance, 
appears to be guided from within, by the feelings and needs of the individual. In fact, the imagination is not quite so free-form as it first seems.

Imagination starts with the accumulation of experience. It draws on the past, combining and creatively reworking elements of it, to open up possibilities, to generate new propositions and new behaviours. It also depends on traditions, and on the sociological environment. Every act of imagination and every creation will always involve some element of collaboration. In university-parlance, we talk of this as 'standing on the shoulders of giants', but in life, this collaboration can be about sharing knowledge, reading, passing on, showing, re-telling, and explaining. This element of sharing knowledge means that we do not have to experience everything ourselves to have the necessary experience from which to leap into the unknown, into the imagination.

Few of the children and adults who work at the brick kilns have been to school. The limitations of this is revealed in all sorts of ways, but mostly it is made obvious in their lack of a rich library of experience and knowledge to call upon to give them a picture of the wider world and its possibilities. Problem solving is also made difficult without a wide reference base. It makes sense, therefore, that if we want to build a strong community through meaningful change, then we must broaden the experiences of its members.

When people are exposed to a range of new ideas, skills, and experiences though the arts and education, they are enabled them to see themselves, others, and the world differently. Although each step may be small in itself, art-making represents a fundamental shift in perspective and capacity. It is akin to the difference between crawling and walking as psychiatrist Dr. George Halasz describes [8].

We kindle curious minds; we put in front of adults and children things that they have never seen, done, or thought of before. We want to support local organisations and communities in encouraging this curiosity so it is further explored through formal education. We run many programs in local schools and invite teachers to work with us in the brick kilns. This is a collaboration, a sharing of knowledge and skills. UEMS told us that after our projects last year many children enrolled in school - a terrific response to their engagement with arts and learning.

But, to be honest, we are sometimes disheartened by the overwhelmingly uninspiring education that is provided to them when they do arrive at school.

All good education engages students in relevant and meaningful learning experiences but many teachers and schools throughout Nepal have yet to understand this. Most fail to nurture curious minds. The norm is rote learning and the limited use of limited resources, and corporal punishment. But worst of all, are the layers of discrimination that separate children from each other and from their desire to learn.

The teachers and communities who support our arts programs and develop from them are wonderful to work with, but for others, change is not welcome. They feel most challenged when asked to imagine, then nurture children who they describe as wild, dirty and low-caste, into their school and into meaningful education. One asked me "what is the imagination?"

Harvard Dean James Ryan, acknowledged that we can't always arrive at our destination without first meeting many obstacles. The question he poses: Couldn't we at least? is one that guides us. Couldn't we at least get the children interested in learning? And couldn't we at least offer teachers as well as students other versions of how education can look and be? Couldn't we at least give some tips and encouragement to teachers to engage students in some dynamic learning? And couldn't we at least take a positive stance on principles of human rights and social justice for the individuals here - even if others are still suffering discrimination?

The even if, even so are the qualifiers we have to accept when all our goals can't be immediately met. We can't effect change in every brick factory, for every person suffering throughout Nepal, but we can at least start here ... awakening critical consciousness to envision and construct a more humane social and cultural world. We invite teachers and community leaders to see the potential and the value in adopting broader, creative, imaginative ways to engage students and engage with them, even if they are not quite ready for it. We call it rattling the cage!

\section{Collaborating for Change}

READ provides community-led libraries and information services throughout rural Nepal. The library, where we worked, is in Badikhel, is an hour's bus journey from Kathmandu, not far from the brick kilns and is a community hub. Our relationship with READ is another of the connections that began with the conference in Nepal and the Nepal School of Social Work.

The longer we spend at READ and in Nepal, the more we learn about entrenched inequality and disadvantage, none more so, than of women and girls. Not only is sexual and family abuse causing concern for UEMS workers in the brick kilns, it is also a concern here in this community and for the people with whom we work. Alcohol fuelled violence, violence sanctioned by class and caste, and how parents-in-laws treat women are recurring topics of conversations.

Entire communities are deeply impacted by violence, which can be further impacted when outdated traditions, behaviours and thinking prevent women and girls, particularly, and the vulnerable in general, from seeking and receiving the support they need. READ is a gentle force for humanizing change and here in Badikhel we witness and experience a strong and vital community of people working together, even if things are still a work in progress. Part of this work in progress was their invitation to me to run a program to help reduce/eliminate violence again women. 
We started a two-day workshop drawing faces. I soon learnt that most in the group were illiterate and many could not yet hold a pencil. 'We can go slowly, and I will show you'. It was incredibly difficult for some to associate the drawing, with a real face.

We know about human development through studies that describe processes that seem to occur and make sense in places where a child has educated/literate parents, has access to games, books, paper, pencil and the outside world. Observation has shown that all children draw and that the stages through which their drawing passes are more or less the same for children of a given age.

To begin our projects, we often have to go to the start of human development in drawing; back to scribbling and making random marks, to arrive at the stage where drawing in the true meaning of the word starts. This takes the child, or the women, to the first stages of developing a schema. In this stage, a drawing of a human figure generally emerges as a head, with legs, and arms but no body.

These two-legged heads are schematic beings drawn in place of the human figure. In developed countries and families where access to education in its broadest sense is the norm, this happens very early. In Nepal, and other developing countries, the schema, the concept, the abstraction of the human into a drawing happens when the person is given access to paper, drawing materials, and someone to teach and encourage them. Amazingly, once it begins in the older person, their progress is fast. It was not long before they learnt how to draw a sari and scarf; they were on their way to representing themselves in their art.
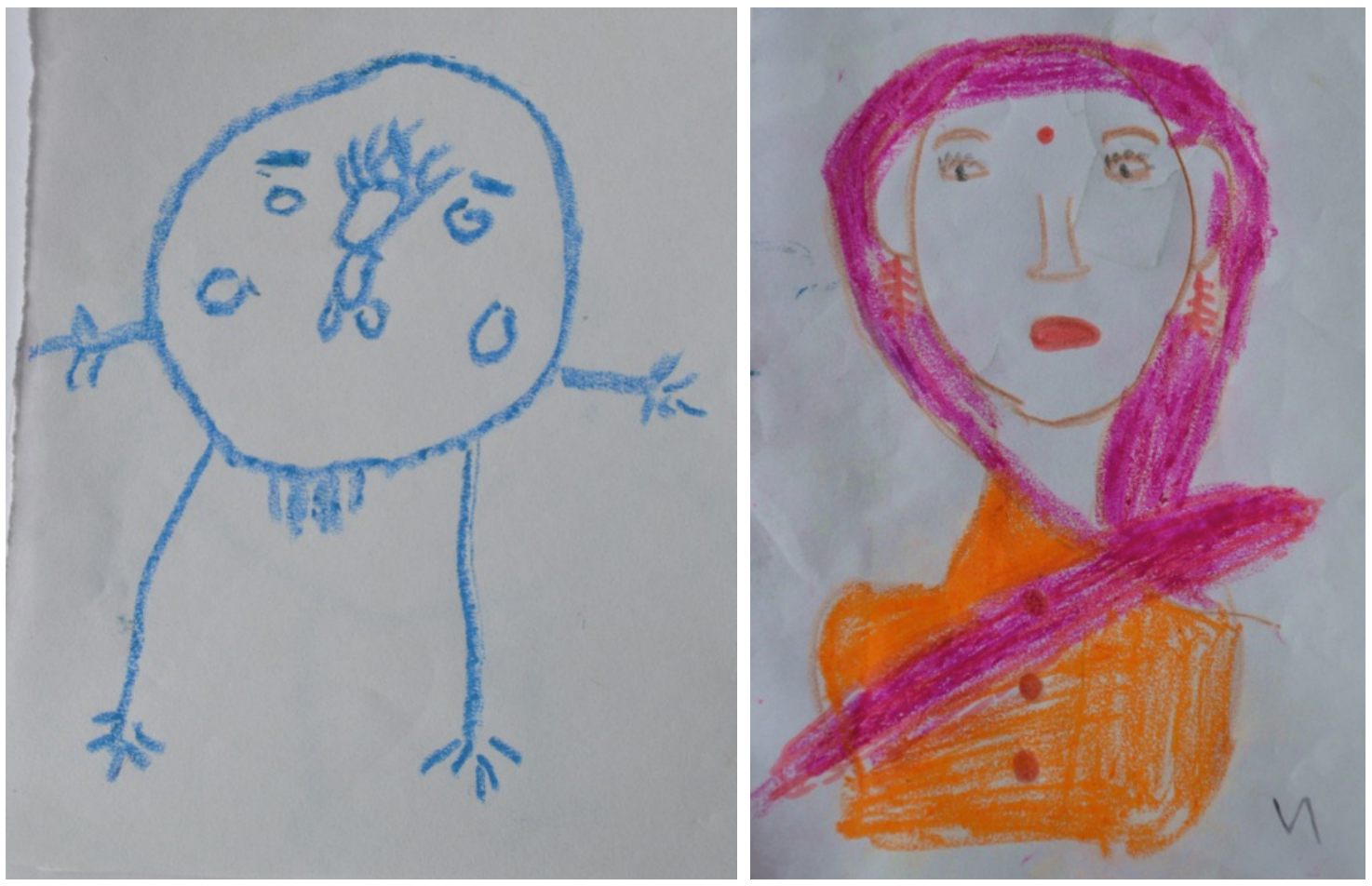

Figure 3. Drawings done by women at the library. The second shows that even with a little training skill quickly improve.

Having spent many months in Nepal now, I see that concepts which I probably previously understood as being instinctive, such as recognizing and understanding shapes (circles, squares, triangles), are simply not universally understood. I realize they have been taught to us. Without these fundamental lessons, the experience I spoke of before, the place upon which the imagination, creative thinking, problem solving, or change can occur is extremely narrow.

And therefore, people are doomed to remain stuck in their present situations.

READ, UEMS and other communities with whom we work have already recognised this need for education and we are part of their $I$ wonder if ... The women not only want to learn, they are excited to learn art; they also wanted to create a large community painting for the library. For inspiration, I show them some Nepali paintings created in a community outside Kathmandu that depict traditional life. They are colourful, simple and easily related to. Over two days the women skills shifted from not being able to draw at all, to this ... 


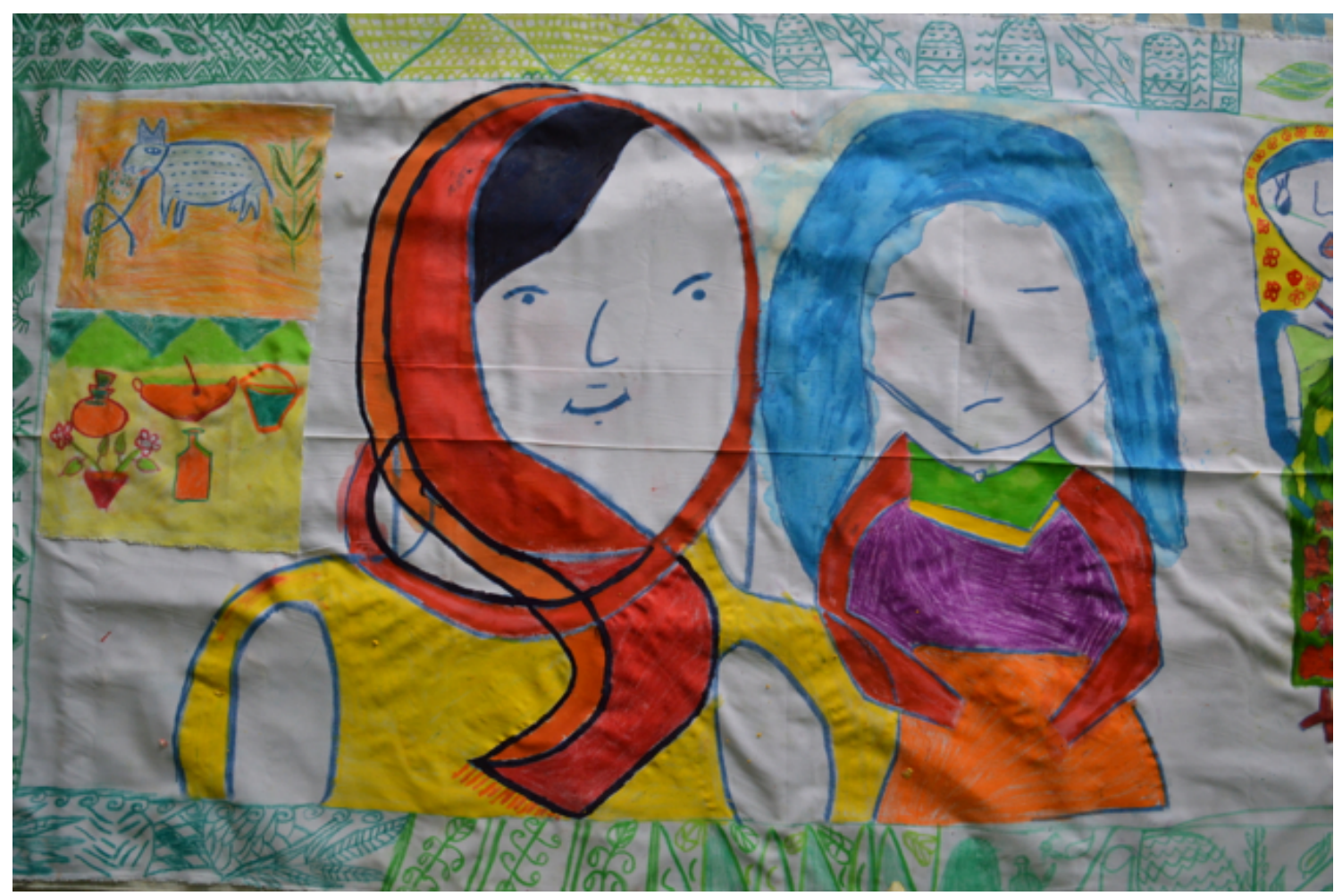

Figure 4. The community painting done by women who only the day before had little or no experience with drawing or painting.

The joy and wonder, the magic of making a personal discovery in this and all our projects is palpable.

So even if we didn't get time to tackle some of the pressing issues around family violence, we did lay the groundwork for that work. By building trust and skills, by learning to draw and paint, to use their imagination, the women learnt something new, and something new about themselves. I am looking forward to seeing where that leads us in another visit.

To choose, we need to know we have a choice. By nurturing the imagination, and encouraging the creative thinking and practice that follows it, we are fostering the principle of freedom.

\section{REFERENCES}

Vygotsky, Lev Semenovich, in "Imagination and Creativity in Childhood". Journal of Russian and East European Psychology, vol. 42, no. 1, January-February 2004, pp. 7-97.
Winterson Jeanette, The Inside Life: on arts funding. Presentation to the Wheelers Centre, Thursday, 19th May 2016 www.wheelercentre.com/notes/the-inside-life-jeanette-winter son-on-arts-funding

Dean James Ryan's 5 Essential Questions In Life https://www.youtube.com/watch?v=bW0NguMGIbE published 29 May 2016.

Lawrence Patrick, 2016 Symphony of Empathy - Artists, imagination and compassion. Published on April 20th, 2016: https://www.linkedin.com/pulse/symphony-empathy-artists-imagi nation-compassion-patrick-lawrence

Calhoun Craig, 2016 Can Imagination Change the World? Public lecture, recorded on 18 February 2016 at Wolfson Theatre, New Academic Building. http://www.lse.ac.uk/newsAnd Media/videoAndAudio/channels/publicLecturesAndEvents/player. aspx?id=3385

Aitken Jonathan, 2013 Margaret Thatcher: Power and Personality, p302. Bloomsbury New York London New Delhi Sydney

Vygotsky, Lev Semenovich, ibid

Halasz George, in conversation with the author, 2010 in The Creative Space. Art and Wellbeing in the shadow of trauma, loss and grief. Anne Riggs, unpublished thesis 2010. 